\title{
TRASCENDENCIA DE LA SOLUCIÓN JURISDICCIONAL DE LOS CONFLICTOS AMBIENTALES INTERNACIONALES
}

\section{IMPORTÂNCIA DA SOLUÇ̃̃O JURISDICIONAL DE CONFLITOS AMBIENTAIS INTERNACIONAIS}

\section{Heber Arbuet-Vignali}

Resumen: El asunto de la protección del ambiente humano se remonta a la aparición del ser humano en la Tierra, pero demora en percibirse como problema hasta mucho después y recién se plantea como cuestión internacional en el siglo XX. Cuando este asunto enfrenta a dos o más Estados la cuestión deberá resolverse y, cuando no alcancen las negociaciones ni los acercamientos, habrá que recurrir a los medios jurisdiccionales. El trabajo se orienta a plantear que características y facultades deben tener los tribunales llamados a actuar en estos casos para poder aportar soluciones satisfactorias y analizar si ellas existen en los actuales sistemas a nivel general y del MERCOSUR.

Resumo: $O$ assunto da proteção do ambiente humano remonta-se à aparição do ser humano na Terra. Contudo, começa a ser percebido como problema muito tempo depois e somente no século XX é colocado como questão internacional. Quando este assunto envolve dois ou mais Estados, a questão deverá resolver-se e, quando nem as negociações nem as aproximações a solucionem, será necessário recorrer aos meios jurisdicionais. O trabalho orienta-se no sentido de apresentar que características e faculdades devem ter os tribunais chamados a atuar nos casos para poder aportar soluções satisfatórias e analisar se elas existem nos atuais sistemas, a nível geral e no Mercosul.

Palabras clave: Protección ambiental, Solución de controversias ambientales Palavras-chave: Proteção ambiental, Solução de controvérsias ambientais

\footnotetext{
* Antiguo Catedrático de Derecho Internacional Público y antiguo Catedrático de Historia de las Relaciones Internacionales en la Facultad de Derecho de UdelaR; antiguo Catedrático de Derecho de la Integración en la Facultad de Derecho de la UDE; Consejero y antiguo Director del Consejo Uruguayo para las Relaciones Internacionales (CURI); premio CONICYT a la investigación jurídica, Nivel III, 1999-2001.
} 


\section{INTRODUCCION}

Esta Revista se dedica, con toda la justicia que naturalmente él merece, al recuerdo y homenaje de Elías Roberto Puceiro Ripoll. Mucho se puede decir de un jurista de su capacidad y de su trayectoria. Para resaltar esas virtudes académicas debe recurrirse a las fuentes que sobre ello hablan mejor que nadie: sus libros, sus artículos, el recuerdo de sus clases y conferencias, sus trabajos profesionales, en los que siguen aprendiendo, y lo harán por mucho tiempo, sus discípulos y sus colegas, entre éstos nosotros.

Pero queremos recordarlo desde una faceta más íntima y entrañable. Hace muchos años, ambos rendimos concurso frente a nuestros maestros y entramos juntos como catedráticos en efectividad en Derecho Internacional Público de Facultad de Derecho UdelaR. Naturalmente estábamos llamados a competir y lo hicimos con ahínco y dedicación. Nunca podré encontrar un competidor más leal, más honesto y más generoso. Eso nos permitió cooperar, trabajar en conjunto y aportar a la Cátedra.

Pero lo más importante a recordar y yo lo haré siempre, es que en un momento determinado, mis posiciones en la Facultad se debilitaron y me enfermé. Quién podría haber sacado mayores ventajas materiales de ello hubiera sido Roberto. En esa ocasión brilló con toda su rutilancia el amigo, uno distinguido entre mis mejores, que siempre lo fue: me acompañó, me ayudó, gestionó mis asuntos, me apoyó y me defendió. Sólo las almas grandes que se ganan la Gloria de Dios, proceden de esa manera.

Para rendirle homenaje he optado por tratar un tema sobre el que él escribió mucho y la pertenece en nuestro tratado, la protección ambiental ${ }^{1}$ mezclándolo con otro que es más próximo a mis esfuerzos y no ajenos a los suyos: la importancia de la solución judicial y el sistema jurídico en la solución de los problemas ambientales.

\section{LOS TRIBUNALES Y EL ESTADO CIVILIZADO Y DE PAZ}

Hobbes y Locke nos cuentan que la sociedad, mientras sólo dispone de la libertad irrestricta, sin reglas ni autoridades, se encuentra en estado de naturaleza y también de guerra; y esto no puede ser de otra forma, ya que sin tales instrumentos que impongan obligaciones para que se garanticen los derechos, sólo la fuerza de cada uno puede concretar el amparo de su felicidad. En esta idea es legítimo incluir a la sociedad internacional conformada por los Estados. Ambos filósofos, también entienden que a partir de la aceptación de reglas, que determinan conductas correctas y prohibidas y legitiman la constitución

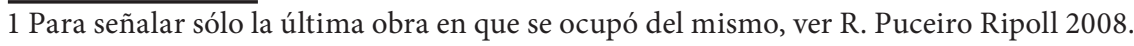


de autoridades que garanticen su cumplimiento, se entra en el estado civilizado.

Pero en el paso siguiente difieren. Hobbes afirma que entrando en el estado civilizado automáticamente se está en estado de paz. En tanto Locke, más fino y perceptivo, dice que con reglas y autoridades se entra al estado civilizado; pero que si entre las autoridades establecidas no existe una que juegue el papel de tercero imparcial, en el que todos o la mayoría confían, y lo aceptan para dirimir sus pleitos privados, y al cual la sociedad proporcione las fuerzas materiales suficientes para hacer cumplir y aún hacer ejecutar coactivamente sus decisiones, es decir que disponga de "jurisdiccio" e "imperium" plenos, se estará en estado civilizado, pero de guerra. Y esto es lógico. Cuando existen reglas y autoridades justificadas por ellas y todos están dispuestos a cumplirlas y acatarlas, aún así, si no existe una autoridad respaldada y respetada que dirima los conflictos particulares y pueda imponer sus veredictos, estos conflictos se definirán en algunos, pocos casos, por el acatamiento del perdidoso de la decisión y en muchos otros, si el perdedor tiene fuerzas suficientes, no acatará el fallo y nada pasará: se está en estado civilizado, pero en definitiva de guerra ya que la fuerza material disponible por cada uno de los involucrados resolverá el asunto.

\section{EL CUIDADO DEL AMBIENTE COMO PREOCUPACIÓN INTERNACIONAL}

En la Tierra siempre existieron actividades contaminantes, fueran de origen natural o humano. Mientras el mundo estuvo poco habitado, resultó ancho y ocupado por quién primero llegara, no es imaginable que el problema se notara. En la Edad Media, y en algunas pocas ciudades antes, cuando aumentó la densidad demográfica en los centros urbanos, el problema se incrementó, pero se dio sólo a nivel local y, de alguna manera controlable. Con la Revolución Industrial, mitad del siglo XVIII a principios del siglo XIX el asunto se extiende y llega a constituir un problema nacional y, excepcionalmente a ser también internacional, en zonas muy industrializadas en el entre cruce de fronteras. Pero esto no se notó

Será después de mediados del siglo XX que la polución ambiental se incrementará como resultado de los adelantos tecnológicos y científicos que aportan mayor amparo y felicidad al ser humano, pero a la vez, en muchas ocasiones, contaminan. Esto llevará el problema al ámbito internacional y un hito demostrativo en este aspecto lo constituye la Conferencia de Estocolmo sobre Medio Ambiente de 1972.

Esta realidad determinó nuevas actitudes y acciones de los Estados, tanto internas como en el marco de las relaciones internacionales. Desde hace bastante tiempo los Estados en su ámbito interno han venido 
adoptando soluciones técnicas y dictando normas jurídicas para evitar o paliar el problema de la contaminación ambiental. Sólo en épocas más recientes han adquirido clara conciencia de que las soluciones internas no son suficientes y que resulta imprescindible una prolija regulación internacional de las numerosas actividades susceptibles de producir contaminación ambiental transfronteriza generalizada.

Antes de la Conferencia de Estocolmo, pero especialmente a partir de su ocurrencia, el mundo, o partes de él, tomaron conciencia de una nueva amenaza y proliferaron los movimientos ambientalistas y las acciones de ONGs preocupadas por ese problema. El aporte muy positivo de sus actividades fue poner el tema en la agenda internacional y el negativo el desbalancear el necesario equilibrio y mutuo aporte entre la protección del ambiente y el desarrollo sustentable.

Hacia fines del siglo XIX aparecen los primeros tratados para la protección ambiental referidos al amparo de los recursos pesqueros, la fauna, la flora y algunos cursos de aguas internacionales; su finalidad última es la protección de bienes económicamente rentables y no precisamente del medio ambiente en sí mismo valorado. A principios del siglo XX se aprueban algunos convenios dónde se marca un sentido más ambiental, como el de 1900 para asegurar la conservación de las especies animales salvajes en las colonias de África o la Convención de 1902 para la protección de las aves útiles a la agricultura. También hay algunos pocos acuerdos bilaterales anteriores o contemporáneos sobre el asunto ${ }^{2}$. El Pacto de la Sociedad de las Naciones no tiene referencias al respecto ${ }^{3}$ y la Carta de la ONU tampoco tiene referencias directas expresas sobre protección del ambiente humano y los recursos naturales, pero estos asuntos se han encarados dentro de marco de su art. 1 inc. $3^{4}$.

La normativa propiamente ambiental se desarrollará a partir de entonces, especialmente después de la Conferencia de Naciones Unidas sobre Medio Humano, de Estocolmo, realizada entre el 5 y 16 de junio de $1972^{5}$.

En cuanto a los conflictos entre Estados por controversias vinculadas al ambiente humano, el primero que conocemos que se llevó a una solución jurisdiccional ocurrió en 1941 entre Canadá y EE.UU. y fue sometido a un tribunal arbitral. Después, la búsqueda de soluciones

\footnotetext{
2 Por ej.: Convenio bilateral de pesca entre Francia y Gran Bretaña de 1867; el tratado sobre aguas fronterizas entre Canadá (Gran Bretaña) y EE.UU. de 1902.

3 Datos extraídos de A. Barreira, P. Ocampo y E. Recio, 2007.

4 "Los Propósitos de las Naciones Unidas son:....3. Realizar la cooperación internacional en la solución de problemas internacionales de carácter económico, social, cultural o humanitario, y en el desarrollo y estímulo del respeto a los derechos humanos y a las libertades fundamentales de todos...”.

5 R. Puceiro, 2008, en su trabajo analiza, además de la Conferencia de 1972 y su Declaración: el Programa de Naciones Unidas para el Medio Ambiente (PNUMA), la Carta Mundial de la Naturaleza de 1982, la Conferencia de Naciones Unidas sobre Medio Ambiente y Desarrollo de 1989 y la Declaración de Río sobre Medio Ambiente y Desarrollo de 1992.
} 
jurisdiccionales se hizo más frecuente, y uno de los últimos casos, que nos toca de cerca y se ha reactualizado en estos tiempos (octubre 2013), es el de las fábricas de pasta de celulosa sobre el río Uruguay (ver H. Arbuet-Vignali y D. Vignali Giovanetti, 2010).

\section{LA SOCIEDAD INTERNACIONAL Y EL ESTADO DE NATURALEZA O CIVILIZADO}

Siempre existieron Centros de Poder independientes ${ }^{6}$ y entre ellos se relacionaron de diferente manera. Antiguamente lo hicieron en el marco geográfico de distintos ámbitos cerrados y aislados entre $s i^{7} \mathrm{y}$, dentro de los cuales había un poder hegemónico que desplegaba su preponderancia. Entre estos conglomerados prácticamente no existían sino escasas relaciones comerciales y culturales y en ocasiones grandes enfrentamientos ${ }^{8}$. No se daban entre ellos relacionamientos generalizados e instituidos. En el interior de esos grupos podía existir un mando ordenador civilizado, pero en sus vínculos con los demás se encontraban en estado de naturaleza y de guerra, sin normas ni autoridades comunes.

Hacia fines del Renacimiento esta situación comienza a modificarse con la aparición de los actuales prototipos de Centros de Poder independiente: los Estados Nacionales ${ }^{9}$. Estos, después de organizar su mando interno a partir de un principio laico y popular, el atributo de la soberanía (ver H. Arbuet-Vignali 2013a) y de desplazar a los poderes feudales internos, quisieron y lograron, quitar el control de las relaciones internacionales de la égida del Papado ${ }^{10}$. Habiendo aparecido las naciones, comienzan a darse entre ellas las relaciones internacionales y, para reglar estas, se va creando y afianzando un sistema jurídico: el Derecho Internacional Público ${ }^{11}$. Este aparece en

6 Los que caracterizamos como grupos humanos cerrados en algún límite; que tienen algún tipo de organización interna de la cual resulta la existencia de autoridades que no dependen de otro Centro de Poder que las subordinen; y que generalmente disponen de un territorio propio o, al menos, se desplazan por uno más extenso que comparten, utilizan o disputan con otros grupos similares. Quedan comprendidos en la idea las hordas, clanes y tribus, las ciudades-Estados, los imperios de la antigüedad, los reinos, ducados, principados y otros estamentos feudales, el Papado y el Imperio, los Estados nacionales, etc.

7 Los reinos e imperios del cercano oriente, el imperio chino, los reinos e imperios del subcontinente indio, Egipto, las ciudades griegas, el ámbito romano, el papado y el imperio medioeval, los imperios de mesoamérica, etc.

8 Las guerras médicas, las guerras de Alejandro, la conquista de las Indias Occidentales.

9 Francia, Inglaterra, España, Suecia-Noruega.

10 Y, en menor medida, del decadente Imperio Romano Germánico.

11 Hasta entonces sólo existía una única clase de sistemas jurídico, los de subordinación que informaban a todos los sistemas jurídicos internos y que se caracterizan por la clara diferencia que establecen entre las autoridades que ordenan y los sujetos que son ordenados. El Derecho Internacional Público, en cambio, es un sistema jurídico de coordinación cuyo destino es regular a unos sujetos que son soberanos, razón por la cual no admiten ser ordenados desde fuera de ellos y por eso este sistema que los ordena y somete irremisiblemente, se caracteriza por 
Westfalia, 1648, se desarrolla en la fuente consuetudinaria, se afirma en Utrecht, 1709-13, vuelve a afirmarse en la vieja fuente consuetudinaria y en los tratados cada vez más numerosos, marca un punto de quiebre con los aportes de la Sociedad de las Naciones y se instala definitivamente en el marco de la Organización de las Naciones Unidas y su sistema de Organismos Especializados, a través de la infinidad de tratados que la Organización genera.

Si recordamos que para salir del estado de naturaleza y de guerra y entrar al estado civilizado es necesario que las sociedades se den normas y autoridades y tomamos en cuenta la evolución del Derecho Internacional Público y sus instituciones, podemos afirmar que la proto sociedad internacional, hasta el siglo XVII se desarrolló en estado de naturaleza y de guerra. También podemos decir que comenzó a dejar, en forma lenta y sostenida, ese estado a medida que se fueron dictando reglas y que con la Sociedad de las Naciones entra en un estado que llamamos semi civilizado, porque se dispone de suficientes reglas comunes, pero aún se carece de autoridades con ese alcance: antes directamente no existían ${ }^{12}$ y las que pretendió aportar la Sociedad de las Naciones, fueron absolutamente ineficaces y no funcionaron nunca como tales. Recién con el sistema de las Naciones Unidas la sociedad internacional sale del estado semi civilizado para entrar en el civilizado porque con ella se aportan suficientes reglas jurídicas y también se establecen autoridades operativas ${ }^{13}$. Esta lenta evolución y las complejas situaciones a que dio lugar, condujo a que la doctrina jus internacionalista se confundiera y aplicara al Derecho Internacional

que en él, son los mismos sujetos reglados quienes participan directamente en todas las etapas del sistema: crean sus normas (tratados y costumbres), vigilan su cumplimiento (actividad diplomática, coordinación de acciones y necesidad de la voluntad del Estado para someterse a sus tribunales) y castigan a sus infractores (auto tutela y después sistema de seguridad colectiva con papel preponderante de los propios Estados). Recién a mitad del siglo XX aparecerá un nuevo sistema jurídico internacional mixto, donde tienen similar importancia las estructuras de subordinación y las de coordinación y que se funda en el Principio de la Supranacionalidad; pero este sistema por ahora sólo funciona a nivel regional (en la Unión Europea y, con dificultades, en la Comunidad Andina). Por otra parte, si bien desde principios del siglo XV existieron normas jurídicas internacionales aisladas que regularon relaciones entre ciudades comerciales, será recién a partir de 1648, con los tratados de Westfalia, que se sienten las bases de un sistema jurídico internacional organizado.

12 Lo más parecido a una autoridad generalizada fue el sistema de la Santa Alianza y del Concierto Europeo, los que en realidad sólo instituyen una sucesión de conferencias internacionales, más o menos previstas, para intentar lograr acuerdos generales en ciertos casos.

13 Esto hay que tomarlo dentro del marco de las posibilidades que permite el ámbito jurídico en que se insertan las Naciones Unidas, el Derecho Internacional Público, un sistema jurídico de coordinación en el cual siempre se requiere para tomar decisiones y ejecutarlas, contar con el respaldo de la voluntad de los Estados. Esto determina algunas debilidades inherentes a su estructura: su sistema de seguridad colectiva está confiado a un órgano político y en él algunos Estados pueden paralizarlo (ver H. Arbuet-Vignali 2012a) y su sistema jurisdiccional se abre sólo si la voluntad de las partes lo aceptan expresa o tácitamente, en cuyo caso la "jurisdictio" es amplia, pero los tribunales sólo tienen "imperium" en el marco internacional y no en el interno de los Estados. 
Trascendencia de la solución jurisdiccional... Heber Arbuet-Vignali

Público una idea de soberanía que "tomara prestada" de las ciencias políticas (y que era hermenéuticamente inaplicable al derecho), con todas las negativas consecuencias y confusiones a que ello dio lugar (ver H. Arbuet-Vignali 2013b, especialmente Numeral 6).

\section{LA SOCIEDAD INTERNACIONAL Y EL ESTADO DE PAZ}

La sociedad internacional general, la que comprende las relaciones entabladas entre los 195 Estados reunidos en Naciones Unidas ${ }^{14}$, y a la que desean pertenecer varias entidades estatales aún no reconocidas, se encuentra en estado civilizado, pero ¿también está en estado de paz en el sentido que al término da Locke? (ver supra 2). Pensamos que no, que en ese sentido está en estado de paz pero a la vez de guerra.

El único sistema jurídico que regula las relaciones de la sociedad internacional general, mundial, es el sistema del Derecho Internacional Público; sistema de coordinación, que se funda y desarrolla a partir del principio de la Igualdad Soberana de los Estados. Siendo un sistema jurídico, cuando entra a funcionar, sus reglas obligan a los Estados sin que éstos puedan desprenderse por su voluntad de esas obligaciones. Por ser un sistema de coordinación, sus reglas no pueden entrar a funcionar sin la previa aceptación, expresa o tácita, de los Estados que quedarán obligados (ver supra nota 13) y la existencia de cualquier diferendo entre Estados no podrá someterse a la resolución de un tercero imparcial, juez o árbitro, si todos los que se someterán a la decisión previamente no aceptan al tribunal. Sin cumplirse esto las partes no podrá ser juzgadas; $y$, cuando lo sean, después de abrir la jurisdicción y condenarse a uno de ellos, si éste no cumple voluntariamente con la sentencia o el laudo, éstos sólo podrán ser ejecutados coercitivamente en el marco internacional ${ }^{15}$, pero no en su ámbito interno, en el de la jurisdicción doméstica del Estado condenado ${ }^{16}$, por lo que muchas veces la decisión jurisdiccional

14 Incluimos a los dos Estados reconocidos por la Organización como observadores: Palestina y Vaticano.

15 Retorsiones, represalias en legítima defensa, eventualmente sanciones, incluso recurriendo al uso de la fuerza armada en el marco del Capítulo VII de la Carta, si el incumplimiento pone en peligro la paz y seguridad internacionales.

16 Un Estado podrá no cumplir con una obligación internacional y será responsable por ello en el marco de la comunidad internacional. Podrá no estar obligado a comparecer ante ningún tribunal internacional, porque no asumió ese compromiso y, en ese caso, ningún tribunal tendrá competencia para obligarlo, aunque para ello pagará fuertes costos políticos, de relacionamiento y en consecuencias, también económicos. Podrá tener que comparecer ante un tribunal internacional, hacerlo y ser condenado, pero posteriormente no acatar el fallo o laudo, ni cumplir con sus disposiciones. Siempre que haya incurrido en la violación de una obligación internacional incurrirá en responsabilidad internacional y el Estado perjudicado estará legitimado para imponerle retorsiones y la comunidad internacional, el perjudicado y sus pares, podrán legítimamente imponerle sanciones a ejecutar dentro del ámbito internacional (retorsiones, represalias en legítima defensa, sanciones en el marco de los Capítulos VI y VII de la Carta). Lo que no se podrá es ejecutar forzadamente la sentencia o el laudo en el ámbito interno del Estado que fue condenado y no acepta cumplirlo, 
puede tornarse ineficaz (ver H. Arbuet-Vignali 2013c), especialmente Numeral 3).

Esta situación se hace tremendamente real y preocupante en los casos en que contiendas por polución ambiental internacional transfronteriza, se lleven ante un tribunal internacional general, la Corte Internacional de Justicia, o ante un tribunal regional, por ejemplo el Tribunal Permanente de Revisión del Mercosur. En estos casos es posible, y además probable, que el tribunal condene a una de las partes y le ordene que cese ciertas actividades realizadas en su ámbito interno ${ }^{17} \mathrm{y}$ que resultan con efectos contaminantes más allá de los límites aceptables y más allá de sus fronteras. Cuando la decisión del tribunal exige que el perdidoso ejecute en su territorio la orden tomando cierto tipo de medidas para restaurar o mejorar la calidad del ambiente pueden darse dos situaciones.

Una primera posibilidad es que el Estado obligado a cumplir acate la decisión y exija a los particulares que están bajo su jurisdicción que tomen las medidas necesarias para ello; si en este caso los particulares no acatan su mandato, el Estado involucrado puede poner al servicio de la ejecución forzada del mismo, todos los instrumentos coercitivos internos de que dispone y obligar a los particulares. En este caso se habrá cumplido el derecho y todo saldrá bien.

Pero la segunda posibilidad se da cuando el Estado condenado, que debe ejecutar la decisión en su territorio, no está dispuesto a acatarla de buena fe. En este caso para obligar al Estado rebelde, el Tribunal dispondrá de instrumentos coercitivos aplicables en el ámbito internacional: imponer sanciones económicas o diplomáticas, por legítima defensa autorizar retorsiones o represalias a los Estados perjudicados o dar cuenta del fallo y su incumplimiento al Consejo de Seguridad de las Naciones Unidas para que este pueda imponer sanciones; no dispondrá en cambio de ningún instrumento que le permita adoptar directamente medidas coercitivas dentro de las fronteras del Estado dónde debe ejecutarse el fallo.

Analicemos la eficacia de estas posibilidades. Cualquiera de las medidas internacionales disponibles, junto al desprestigio que alcanzará al Estado por su actitud rebelde, generalmente son eficaces y suficientes para obligarlo a rever su posición y acatar los fallos recaídos en aquellos asuntos normales al Derecho Internacional Público de todos los tiempos

porque hacerlo significaría la intervención en sus asuntos internos, atacaría los Principios sustentantes del Derecho Internacional Público y le destruiría. Para que pueda accederse a esa posibilidad, lo que nosotros recomendamos, debe transitarse del Derecho internacional Público fundado en el atributo de la Soberanía, a otro tipo de sistema fundado en el atributo de la Supranacionalidad. Lo que es posible y debe hacerse, al menos para ciertos asuntos.

17 Por ejemplo: que deje de utilizar ciertos medios de producción; que no use determinados productos químicos; que rebaje su producción a niveles menores; que adopte medidas sanitarias para re purificar el ambiente agredido; etc. 
y que aún se producen (problemas de límites, de desconocimiento de prerrogativas diplomáticas, de responsabilidad internacional, etc.). No ocurre lo mismo cuando la materia en que recae el fallo, como en los casos de conflictos ambientales, esté directamente vinculada con los nuevos riesgos que nos ha traído la nueva civilización (contaminación, protección de los derechos humanos, delitos internacionales, orientación del comercio, etc.) y las consecuencias de la decisión alcanza a particulares. Dada la magnitud de los daños que en estos casos producen los incumplimientos, esperar a que el Estado infractor sienta los perjuicios que le produce el desprestigio o las sanciones económicas o diplomáticas y cambie de actitud, más que peligroso sería suicida. Las retorsiones y las represalias son inimaginables para estos casos, ¿o es que alguien piensa que si un Estado deja funcionar una industria contaminante, el otro perjudicado pueda autorizar el funcionamiento de varios emprendimientos más contaminantes aún?. Sólo plantear la hipótesis pone en evidencia su absurdo. Por último respecto al recurso al Consejo de Seguridad, además de que sólo se podría llegar a él en casos extremos (cuando a consecuencias del incumplimiento se diera la posibilidad o se abriera un conflicto armado entre las partes de tal magnitud que pueda extenderse a la región, al continente o al mundo), no debe olvidarse que el Consejo es un órgano político en el cual cinco Estados tienen derecho a veto, lo qué no constituye ninguna garantía para la objetividad requerida por las acciones jurisdiccionales.

Además los tribunales internacionales, arbitrales o judiciales, no pueden ejercer directamente coerción en el ámbito interno de los Estados (ni siquiera en el citado caso del Consejo de Seguridad, dónde están condicionados a las circunstancias y a la voluntad política, lo cual no da seguridades jurídicas) para obligar a cualquiera de ellos. Pretender hacerlo no sería legítimo ni congruente, ya que para ejecutar una sentencia del Derecho Internacional Público, se desconocerían y atacarían los Principios que fundan y permiten funcionar al propio sistema: la Igualdad Soberana de los Estados, la No Intervención en los Asuntos Internos y la existencia de un Ámbito de Jurisdicción Doméstica excluyente. Si así se hiciere, por ejecutar un fallo del sistema, se violarían los Principios fundamentales del mismo y le destruirían, lo cual, jurídicamente no es pensable.

En los casos en los cuales se pretendiera resolver con operatividad real conflictos ambientales transfronterizos, sólo sería eficaz un fallo que proviniera de un tribunal que dispusiera de poderes coercitivos internacionales y que también dispusiera de instrumentos coercitivos operantes en el ámbito interno de los Estados. Esta posibilidad no la brinda, ni la puede brindar por su estructura, el Derecho Internacional Público. Pero el Derecho Internacional Público, que continúa manteniendo utilidad para resolver sus problemas tradicionales, también 
es el único instrumento jurídico que permite crear un sistema más comprometedor para los Estados, un sistema que se basara en el Principio de la Supranacionalidad y permitiera trasladas poderes de gobierno de los Estados hacia Organizaciones Internacionales supranacionales. En conclusión es necesario disponer de un nuevo sistema que permita controlar y encausar una serie de nuevas actividades que últimamente se dan en las relaciones internacionales, para de esta manera procurar evitar o minimizar los graves riesgos que ellas producen. Para ello no se dispone en la actualidad, a nivel mundial, ni regional interamericano, ni en el subregional del Mercosur, de un sistema jurídico apropiado, que sea más compromisorio que el actual y que disponga de más fuertes medios de ejecución y, para crearlo, deberá recurrirse a los instrumentos que brinda el actual sistema, el Derecho Internacional Público.

\section{LA PROTECCIÓN AMBIENTAL, EL MERCOSUR Y EL TRIBUNAL PERMANENTE DE REVISIÓN}

La normativa ambiental en Mercosur no es demasiado abundante $e^{18}$, pero ello no crea un problema mayor, habida cuenta que todos sus Estados partes están vinculados por los principales Acuerdos Generales sobre el tema, lo cual los hace aplicables. Hay dos acuerdos que importan: el Acuerdo Marco sobre Medio Ambiente del Mercosur, aprobado por Decisión del Consejo Mercado Común 02 del 2001 y el protocolo Adicional al mismo para el caso de Emergencias Ambientales de Foz de Yguazu de julio de 2004.

En el primero las partes reafirman su compromiso con los Principios esenciales de la Declaración de Río de Janeiro de 1992 y se comprometen a tratar de instrumentarlos; se establecen también, para lograr el objeto del acuerdo seis líneas de conducta a seguir (arts. 1 a 3); el objeto del compromiso se describe en el art. 4 y se ubica en "...el desarrollo sustentable y la protección del medio ambiente...; en los arts. 5 a 7 se sientan las reglas para la cooperación en materia ambiental; y el art. 8 dispone: "Las controversias que surgieran entre los Estados Partes respecto a la aplicación, interpretación o incumplimiento de las disposiciones contempladas en el presente Acuerdo serán resueltas por medio de Sistema de Solución de Controversias vigente en el Mercosur". Y el sistema de solución de controversias del Mercosur se establece en el

18 El tratado de Asunción sólo refiere al tema en su Preámbulo, diciendo que la protección ambiental es un medio para lograr los objetivos del Acuerdo; la Decisión 9/95 que establece el Programa de Acción del Mercosur para el año 2000, también se ocupa del mismo y se remite a la Conferencia de las Naciones Unidas para el Medio Amiente de Río de Janeiro 1992; el Acuerdo Marco y el Protocolo Adicional al mismo que se verán de inmediato; la Declaración de Taranco hecha en la Reunión de Ministros de Medio Ambiente en Montevideo 1995; y también se hacen referencias en los Acuerdos del Mercosur con la Comunidad Europea de 1995 y con Canadá de 1998. Hay por otra parte variadas declaraciones de los Grupos de Trabajo. 
Protocolo de Olivos, cuyo Capítulo VII, consagra el procedimiento de revisión y crea el Tribunal Permanente de Revisión ${ }^{19}$.

De todo lo que antecede debe concluirse de que en materia de conflictos ambientales la sociedad internacional regional que reúne a los Estados partes del Mercosur, se encuentra en estado civilizado ya que dispone de un sólido soporte de normas jurídicas convencionales, las cuales consagran la existencia de autoridades claramente establecidas, con competencias y poderes específicos, entre las cuales se dispone de órganos jurisdiccionales: los que resultan del procedimiento arbitral ad hoc (Protocolo de Olivos, Capítulo VI, arts. 9 a 16 y los que resultan del ya mencionado procedimiento de revisión, del Capítulo VII, arts. 17 a 24 .

¿Podemos decir también que se encuentra en estado de paz, en el sentido que, para el caso, atribuye Locke a este término?

\section{CONCLUSIONES}

\subsection{Marco jurisdiccional del Mercosur}

La interrogante abierta es la que debe resolverse $y$, en caso necesario, indicar que hace falta hacer para que, en materia de asuntos de protección ambiental, en el marco del Mercosur, se alcance el deseado estado civilizado y de paz. Nadie puede discutir que el sistema jurídico del Mercosur, aún debilitado por decisiones políticas (ver H. ArbuetVignali 2012b), tiene una sólida base normativa vigente y dispone de autoridades que lo conducen, inclusive de órganos jurisdiccionales. También resulta claro que su sistema se inserta en el marco del Derecho Internacional Público, fundado y estructurado a partir del Principio de la Soberanía, y que es ajeno a cualquier tipo de sistema fundado en el atributo de la Supranacionalidad (ver H. Arbuet-Vignal 2004, Capítulo VI, especialmente Secciones II y IV). También resulta claro que el Mercosur, sin modificaciones previas en las constituciones de algunos de sus Estados partes, no puede acceder a este tipo de sistemas: porque las constituciones de Brasil y Uruguay no permiten a estos Estados derivar poderes de gobierno nacionales a Organizaciones Internacionales; porque, si bien las constituciones de Argentina y Paraguay, sí lo admiten, lo condicionan a la reciprocidad, la que, por lo anterior no puede ofrecerse ${ }^{20}$; y porque la constitución de Venezuela, que no es clara, en

19 El Protocolo de Olivos para la solución de controversias en el Mercosur del 18 de febrero de 2002, puede verse en E. J. Rey Caro 2002.

20 Las disposiciones sobre la voluntad de integración, incluso supranacional, son claras y expresas en las constituciones argentina y paraguaya que regulan la posible delegación de competencias y poderes de gobierno a órganos internacionales atribuyéndoles el atributo de la supranacionalidad: Argentina, art. 77 inc. 24: "Corresponde al Congreso... Aprobar tratados de integración que deleguen competencias y jurisdicción a Organizaciones supraestatales en 
forma confusa, permitiría la supranacionalidad sin condicionamiento expreso $^{21}$.

En consecuencia, el conjunto de procedimientos y órganos jurisdiccionales que prevé el Protocolo de Olivos en sus Capítulos V a VII se insertan en el sistema del Derecho Internacional Público, con sus características y limitaciones (ver H. Arbuet-Vignali, 2005, Secciones II y III).

En definitiva puede afirmarse que el conjunto de las relaciones internacionales regionales establecidas por el grupo de Estados reunidos en el Mercosur y referidas a la protección ambiental, a las que deben agregarse las demás comprendidas en otros ámbitos de competencias, se encuentran en estado civilizado, porque se dispone de suficientes normas y de autoridades que las aplican y conducen el grupo. ¿Puede decirse que también se encuentran en estado de paz?

\subsection{La solución de las controversias en el Mercosur}

El Mercosur siempre dispuso de un sistema para resolver sus controversias. Primero aquel que R. Puceiro (2002, p. 31), llama "embrionario" y se pacta en el Tratado de Asunción, después el arbitral del Protocolo de Brasilia y, por último, el más desarrollado del Protocolo de Olivos.

Nos ocuparemos de este último por ser el que actualmente

condiciones de reciprocidad e igualdad y que respeten el orden democrático y los derechos humanos. Las normas dictadas en su consecuencia tienen jerarquía superior a las leyes" (se exige diferente "cuorum" para aprobarlas); y Paraguay: art. 145: "La República del Paraguay en condiciones de igualdad con otros Estados, admite un orden jurídico supranacional que garantice la vigencia de los derechos humanos, de la paz, de la justicia, de la cooperación y del desarrollo en lo político, económico, social y cultural". No se hacen referencias directas a esta posibilidad en las constituciones de Brasil y de Uruguay, siendo más explícita la primera. Dice el art. 4 de la Constitución de Brasil: "La República Federativa de Brasil procurará la integración económica, política, social y cultural de los pueblos de América Latina, procurando la formación de una comunidad latinoamericana de Naciones". Más débil es la referencia de la Constitución de Uruguay en el art. 6 inc. 2: "La República procurará la integración social y económica de los Estados Latinoamericanos, especialmente en lo que se refiere a la defensa común de sus productos y materias primas. Asimismo propenderá a la efectiva complementación de sus servicios públicos".

21 Artículo 153. La República promoverá y favorecerá la integración latinoamericana y caribeña, en aras de avanzar hacia la creación de una comunidad de naciones, defendiendo los intereses económicos, sociales, culturales, políticos y ambientales de la región. La República podrá suscribir tratados internacionales que conjuguen y coordinen esfuerzos para promover el desarrollo común de nuestras naciones, y que garanticen el bienestar de los pueblos y la seguridad colectiva de sus habitantes. Para estos fines, la República podrá atribuir a organizaciones supranacionales, mediante tratados, el ejercicio de las competencias necesarias para llevar a cabo estos procesos de integración. Dentro de las políticas de integración y unión con Latinoamérica y el Caribe, la República privilegiará relaciones con Iberoamérica, procurando sea una política común de toda nuestra América Latina. Las normas que se adopten en el marco de los acuerdos de integración serán consideradas parte integrante del ordenamiento legal vigente y de aplicación directa y preferente a la legislación interna. 
está en vigor. En él, además de lo que Puceiro (2003, p.193), llama "procedimientos cuasi jurisdiccionales" ante el Grupo Mercado Común, el Protocolo abre la competencia de los tribunales arbitrales ad hoc (art. 9 inc. 1) a las controversias entre Estados partes sobre la interpretación, aplicación o incumplimiento de las disposiciones del Tratado de Asunción, el Protocolo de Ouro Preto, de los Protocolos celebrados en el marco del Tratado de Asunción, de las Declaraciones del Consejo Mercado común, de las Resoluciones del Grupo Mercado común, de las Directivas de la Comisión de Comercio del Mercosur, las que podrán ser sometidas a los procedimientos del Protocolo de Olivo.

También el art. 17, inc. 1, dispone que el Tribunal Permanente de Revisión atenderá en los recursos de revisión interpuestos contra los laudos de los tribunales arbitrales ad hoc, aunque esto sólo podrá hacerse con respecto a "las cuestiones de derecho tratadas en la controversia y a las interpretaciones jurídicas desarrolladas en el laudo" (art. 17 inc. 2).

Además, y por último, en el art. 23 se consagra la competencia directa del Tribunal Permanente de Revisión, cuando las partes, después de concluir las negociaciones entre sí (arts. 4 y 5), acuerden someterse directamente y en única instancia al TPR.

Como, por su parte, el Acuerdo Marco sobre medio ambiente del Mercosur (ver supra 6, párrafos 1 y 2), somete las controversias ambientales a la resolución del sistema de solución de controversias del Mercosur, podría sostenerse la existencia en el de un estado de paz.

\section{3. ¿Existe un estado de paz en el sistema?}

No pensamos que sea así. Si bien el sistema se encuentra en estado civilizado pensamos que se continúa en estado de semi guerra o semi paz. Es correcto sostener que no se carece de terceros imparciales para resolver los conflictos, órganos jurisdiccionales tales como los tribunales ad-hoc y el Tribunal Permanente de Revisión y que la ocurrencia ante ellos no requiere un acuerdo previo en cada caso, sino que resulta obligatorio si una de ellas lo deciden y se han cumplido ciertas instancias (arts. 4 a 9). También es correcto sostener que todo ello se enmarca dentro del marco del Derecho Internacional Público, un sistema fundado en el atributo de la soberanía y que excluye el atributo de la supranacionalidad. Por esta razón, en última instancia, cuando un laudo no sea cumplido por iniciativa del obligado y deban ser ejecutados coercitivamente dentro de la jurisdicción interna del Estado condenado, esto no podrá hacerse por la Organización ya que, si lo intentara, violaría los Principios que sustentan el sistema dentro del cual actúa ${ }^{22}$ y, por lo tanto, lo destruiría

22 El principio de la Igualdad Soberana de los Estados, aceptado desde el comienzo del Derecho Internacional Público en los tratados de Westfalia, recogido expresamente en los tratados de Utrecht y que funda el sistema de las Naciones Unidas según el art. 2 inc. 1 de la 
(ver H. Arbuet-Vignali 2013c, Numeral 3). En estos caso la ejecución forzada para hacer cumplir el contenido del fallo resultaría imposible y la superioridad del Derecho Internacional resultaría de que, en el ámbito de las relaciones internacionales, se le impondrían sanciones, indemnizaciones, retorsiones o represalias ${ }^{23}$ (ver $\mathrm{H}$. Arbuet-Vignali 2013c, Numeral 3), pero nada más. Ello es así porque en definitiva la jurisdicción de los tribunales del Derecho Internacional Público es de apertura voluntaria ${ }^{24}$, si bien disponen de "jurisdictio" plena ${ }^{25}$, su "imperium" 26 se extiende al ámbito de las relaciones internacionales, pero no existe en el ámbito de la jurisdicción doméstica de los Estados. Tenemos que afirmar que en este marco se está en estado civilizado, pero con muchas posibilidades de caer en estado de guerra, lo cual no es deseable, ni bueno.

\section{4. ¿Es posible superar esta situación?}

En primer término nos permitimos afirmar que en nuestro concepto sería muy positivo que ello ocurriera, porque una jurisdicción para la solución de las controversias instalada dentro del marco del Derecho Internacional Público, nunca resultará totalmente adecuada para solucionar satisfactoria y definitivamente un problema internacional de contaminación ambiental transfronteriza. Para mostrar sus carencias bastará que una de las partes no cumpla de buena fe el laudo o fallo; y que estas cosas ocurren puede ser constatado atendiendo a lo que está sucediendo (octubre 2013) respecto a la ejecución del fallo de la Corte Internacional de Justicia en el caso $\mathrm{N}^{\circ} 135$, entre argentina y Uruguay, en el asunto de las fábricas de paste de celulosa sobre el río Uruguay.

La única respuesta adecuada para superar estos problemas resulta de ubicar el sistema de solución de controversias para asuntos ambientales, en el marco de un sistema supranacional, que otorgue a la organización la posibilidad de ejercer poderes de gobierno y a sus tribunales la competencia y la posibilidad fáctica de ejecutar coercitivamente sus fallos o, en el caso del Mercosur, sus laudos, también en el ámbito de la jurisdicción doméstica de sus Estados partes.

Para que el sistema Mercosur pueda transitar avanzando hacia un

Carta y de sus corolarios, especialmente el Principio de no Intervención en los Asuntos de la Jurisdicción Doméstica.

23 Las retorsiones son impensables en materia de protección ambiental y las demás resultan generalmente ineficaces, suelen perjudicar también a quién las aplica y no condicen con un propósito de integración.

24 En este caso la voluntad de los Estados miembros del Mercosur manifestada en el Tratado de Asunción, los demás del sistema y, especialmente, el Protocolo de Olivos.

$25 \mathrm{La}$ decisión del tribunal en su última instancia resulta definitiva y jurídicamente lo que resuelve es una verdad inamovible.

26 Legitimación para recurrir al uso de la fuerza para imponer sus decisiones y disponibilidad de respaldo fático para hacerlo. 
ordenamiento jurídico basado en el atributo de la supranacionalidad veo dos caminos, ambos difíciles de seguir en la realidad política, pero no imposibles dentro de ella: uno aparentemente más corto, pero en la realidad azas difícil de concretar; y otro que requeriría un tránsito más largo, pero quizá más accesible.

El primero consistiría en adecuar el sistema Mercosur, modificando los acuerdos y dotándolo de los instrumentos jurídicos supranacionales necesarios para cumplir con las ilusiones que alimentan las menciones a la creación de una comunidad, el establecimiento de un mercado común, la constitución de una unión aduanera y el arribo a otros logros comunitarios, aunque el sistema jurídico que se adopta no es el adecuado para ello.

No es que el sistema del Derecho internacional Público, fundado en el atributo de la soberanía, impida definitivamente lograr esos avances, pero para que ellos se concreten sería necesario que sus actores actuara con tanta responsabilidad y seriedad, con tanto equilibrio y ponderación en la actividad de los conductores, que se dieran tantas casualidades felices, que no se diera ninguna complicación ni desavenencia, que resulta ingenuo pensar que ello pueda darse en la realidad. Para que este avance realmente se de, se debe transitar hacia un sistema jurídico fundado en el atributo de la supranacionalidad, que la Organización disponga realmente de poderes de gobierno, que las normas que dicte sean prevalente y tengan eficacia directa y que sus tribunales dispongan de la fuerza necesaria para hacer ejecutar coactivamente sus laudos.

En el ámbito del Mercosur este tipo de avances resulta difícil de concretar porque, para ello, hay Estados que previamente deben modificar sus constituciones (ver supra 7.1) y, fundamentalmente, porque sus sistemas constitucionales presidencialistas y las posiciones políticas internas hacen poco factible que esos Estados aporten la voluntad política necesaria para concretar acuerdos que les obliguen a cumplir con las decisiones de la Organización sin tener la posibilidad jurídica de liberarse pagando indemnizaciones o sufriendo sanciones.

El segundo se daría si, como ocurrió en las Comunidades Europeas (ver P. Pescatore 1973), un tribunal del sistema (en el caso el TPR), asumiera la responsabilidad de interpretarlo y pudiera encontrar en el, como creemos que se puede, elementos que abran las vías de la supranacionalidad; y ese tribunal fuera expresándolo en sus laudos, creara conciencia de la especificidad del sistema, obligara a los Estados partes a asumir sus responsabilidades respecto al fenómeno que han creado y les conduzca a ajustar sus constituciones en los casos necesarios (o a retirarse del sistema si no lo hacen), contribuyendo a la formación de un acuerdo por vía consuetudinaria.

También este camino es difícil de recorrer, especialmente porque 
el Tribunal Permanente de Revisión ha registrado poca actividad ${ }^{27}$ y en el caso 01/2012 en que, por sus características tuvo la oportunidad de hacer una evaluación general del sistema, se limitó a enfocar sólo asuntos formales de competencia (ver H. Arbuet-Vignali 2012c). No obstante, una opinión disidente en minoría, abre la esperanza de que se transite por ese camino, lo que a nuestro entender, podría ser importante.

Agradecimiento: $\mathrm{Mi}$ reconocimiento al Dr. Fausto Vieira Coutinho de la Embajada de Brasil en Montevideo, por su apoyo lingüístico.

\section{REFERENCIAS BIBLIOGRÁFICAS}

ARBUET-VIGNALI Heber (2004) Claves jurídicas de la integración. Buenos Aires: Rubinzal-Culzoni Editores.

ARBUET-VIGNLI Heber (2005) "La sociedad y el orden jurídicos internacionales”. En JIMÉNEZ DE ARÉCHAGA Eduardo, ARBUETVIGNALI Heber y PUCEIRO RIPOLL Roberto. Derecho internacional público: principios, normas, estructuras, tomo I. Motevideo: Fundación de Cultura Universitaria, p. 23-81.

ARBUET-VIGNALI Heber (2012a) Intervenir o actuar. El uso lícito de la fuerza armada. Estudios del CURI 01/12. Montevideo: CURI. [online] disponible en: <http://curi.org.uy/archivos/ estudiodelcuri01del12arbuet.pdf $>$ [acceso noviembre de 2013].

ARBUET-VIGNALI Heber (2012b) Crisis en Paraguay ¿o en los conceptos políticos y jurídicos de la región? Estudios del CURI 04/12. Montevideo: CURI. [online] disponible en: <http://curi.org.uy/archivos/ Estudiodelcuri04del12Arbuet.pdf $>$ [acceso noviembre de 2013].

ARBUET-VIGNALI Heber (2012c) Laudo 01/2012 del T.P.R. Un vacío imposible de llenar. Estudios del CURI 08/12. Montevideo: CURI. [online] disponible en: <http://curi.org.uy/archivos/ Estudiodelcuri08del12arbuetvignali\%20rev\%20mi\%C3\%A9rcoles.pdf > [acceso noviembre de 2013].

ARBUET-VIGNALI Heber (2013a) Teoría jurídica de la soberanía. Y su influencia en la doctrina del Estado posmoderno. Inédito.

ARBUET-VIGNALI Heber (2013b) "Un concepto entre las brumas. La construcción de la soberanía en las ciencias jurídicas". Revista de Derecho Público, 22(43), p. 9-32. [online] disponible en: <http:// www.revistaderechopublico.com.uy/archivos/43/Arbuet.pdf> [acceso noviembre de 2013].

ARBUET-VIGNALI, Heber (2013c) Necesidad de un nuevo sistema jurídico para las relaciones internacionales posmodernas. Estudios del CURI 02/13. Montevideo: CURI. [online] disponible en: <http://curi.

27 Después de 9 años de instalado ha actuado en alzada en 5 casos y en jurisdicción directa en 1 . 
org.uy/archivos/estudiodelcuri02del13arbuetx.pdf $>$ [acceso noviembre de 2013].

ARBUET-VIGNALI Heber y VIGNALI GIOVANETTI Daniel (2010) Corte Internacional de Justicia. Caso 135. Estudios del CURI 03/10. Montevideo: CURI. [online] disponible en: <http://curi.org.uy/archivos/ Estudio03del10arbuet.pdf $>$ [acceso noviembre de 2013].

BARREIRA Ana, OCAMPO Paula y RECIO Eugenia (2007) Medio ambiente y derecho internacional. Una guía práctica. Madrid: Caja Madrid/Obra Social.

PESCATORE Pierre (1973) Derecho de la integración. Nuevo fenómeno en las relaciones internacionales. Buenos Aires: BID-Intal.

PUCEIRO RIPOLL Roberto (2002) Exposición del Dr. Roberto Puceiro Ripoll. "Jornada Académica sobre el Protocolo de Olivos para la solución de las controversias en el Mercosur", 10 de junio de 2002, Montevideo. Montevideo: ALADI, p. 31-40.

PUCEIRO RIPOLL Roberto (2003) "Protocolo de Olivos: sus reformas esenciales y su significado en el régimen de solución de controversias del Mercosur". En BRASIL. CONGRESSO NACIONAL. CÂMARA DOS DEPUTADOS Solução de controvérsias no Mercosul. Brasilia: Congresso Nacional. Câmara dos Deputados, p. 189-208.

PUCEIRO RIPOLL Roberto (2008) "La preservación internacional del medio ambiente natural”. En JIMÉNEZ DE ARÉCHAGA Eduardo, ARBUET-VIGNALI Heber y PUCEIRO RIPOLL Roberto. Derecho internacional público: principios, normas, estructuras, tomo II. Motevideo: Fundación de Cultura Universitaria, p. 43-76.

REY CARO Ernesto J. (2002) El Protocolo de Olivos para la solución de controversias en el Mercosur. Córdoba: Marcos Lerner Editora Córdoba. 